\title{
Pelatihan Zotero Guna Menunjang Luaran KKN Tematik Mahasiswa Universitas Pendidikan Indonesia Melalui Whatsapp Group
}

\author{
Syifaul Fuada \\ Program Studi Sistem Telekomunikasi, Universitas Pendidikan Indonesia \\ Email: Syifaulfuada@upi.edu
}

\begin{abstract}
ABSTRAK
Salah satu luaran dari kegiatan Kuliah Kerja Nyata Tematik Pencegahan dan Penanggulangan Dampak Covid-19 (KKNT PPD Covid-19) di Universitas Pendidikan Indonesia (UPI) Tahap II Tahun 2020 adalah berupa karya tulis ilmiah (Laporan KKNT, Book chapter atau artikel jurnal). Selain mengabdi di daerah/tempat tinggal masing-masing, mahasiswa yang menempuh KKNT harus melaporkan aktivitasnya dalam tulisan akademik. Tujuan dari penyelenggaraan kegiatan ini adalah memfasilitasi mahasiswa dalam menyiapkan luaran pengabdiannya. Fokus materi pelatihan adalah mengelola referensi menggunakan perangkat lunak Zotero. Sasaran pelatihan adalah terbatas pada kelompok VIII KKNT, yaitu 29 mahasiswa yang terbagi atas 19 mahasiswa PGSD dan 10 mahasiswa PGPAUD UPI Kampus Purwakarta. Observasi awal menunjukkan bahwa peserta belum pernah menggunakan Zotero sebelumnya, sehingga materi pelatihan ini adalah baru bagi mereka. Whatsapp dipilih sebagai media pelatihan karena praktis dan mendukung kondisi internet masing-masing peserta. Pelatihan di Whatsapp grup berlangsung 1 kali pertemuan dengan 7 kompetensi, berdurasi 5 jam atau setara 300 menit kegiatan KKNT. Hasil menunjukkan $30 \%$ dari peserta pelatihan cukup terbantu dalam mengelola sitasi menggunakan Zotero. Kegiatan pelatihan mengelola Zotero menggunakan media Whatsapp Group ini merupakan kali pertama dilaksanakan di Indonesia, karena umumnya pelaksanaan via Videoconference (tatap maya) atau dilaksanakan secara face-to-face (tatap muka). Sebagai implikasi dari pelatihan daring ini, mahasiswa mampu menguasai Zotero untuk mengelola referensi karya tulis mereka meskipun pelatihan berbasis tekstual (instruktif) di media Whatsapp Group.
\end{abstract}

Kata kunci : Whatsapp, Zotero, KKN Tematik, Karya Tulis IImiah

\section{ABSTRACT}

One of the Thematic Real Work Lecture's outcomes on the Prevention and Overcoming of the Covid-19 impact (KKNT PPD Covid-19) at the Universitas Pendidikan Indonesia (UPI) Phase II, 2020, is scientific papers (KKNT reports, book chapters, or journal articles). Apart from serving in their respective regions/residences, students who take KKNT must report their activities in academic writing. The purpose of this workshop is to facilitate students in preparing their outcomes. The focus of this workshop material is managing references using the Zotero software. The workshop target is limited to group VIII KKNT (29 students) divided into 19 PGSD students and 10 PGPAUD students of UPI Purwakarta Campus. Initial observations indicated that the participants had never used Zotero before, so this workshop was new. Whatsapp was chosen as an online workshop medium because it is practical and supports each participant's internet conditions. The online workshop on Whatsapp Group occurs in 1 meeting with seven competencies, lasts 5 hours or the equivalent of 300 minutes of KKNT activities. The results showed that $30 \%$ of the workshop participants were quite helpful in managing citations using Zotero. This reference manager (Zotero) workshop using Whatsapp Group media is the first time conducted in Indonesia because we found that generally it is carried out via Videoconference or by face-to-face. As an implication of this online workshop, students can master Zotero to manage their references even though the training is textual-based (instructive) in the Whatsapp Group media.

Keywords: Whatsapp, Zotero, Thematic Real Work Lecture, Scientific paper 


\section{PENDAHULUAN}

Kuliah Kerja Nyata (KKN) Tematik merupakan mata kuliah yang mengarahkan mahasiswa untuk masuk/terlibat ke lingkungan masyarakat secara langsung dengan orientasi pelayanan/pengabdian terfokus pada sektor tertentu sesuai dengan masalah di masyarakat sasaran (info, n.d.). Namun pada masa pandemi Covid-19, beberapa Perguruan Tinggi tidak melakukan aktivitas secara luring untuk meminimalisir/mencegah penularan virus. Universitas Pendidikan Indonesia (UPI) adalah salah satu perguruan tinggi negeri berlokasi di Jawa Barat tetap melaksanakan kegiatan KKNT ditengah pandemi Covid-19 secara daring di wilayah tempat tinggal masing-masing mahasiswa, atau KKN Mandiri. Adapun tema yang diusung KKNT UPI adalah Pencegahan dan Penanggulangan Dampak (PPD) Covid-19 dengan program di tiga sektor, yaitu Pendidikan sebagai program wajib, kemudian Ekonomi dan Kesehatan sebagai pilihan (Buku Pedoman Kuliah Kerja Nyata Tematik Pencegahan Dan Penanggulangan Dampak Covid-19 Universitas Pendidikan Indonesia, n.d.). KKNT di UPI Tahun 2020 ditempuh oleh mahasiswa semester VII dengan durasi kegiatan pengabdian selama 30 hingga 50 hari terhitung sejak 17 November 2020. Kegiatan dengan dengan akumulatif wajib 120 jam ini dihargai 2 SKS. Dosen Pembimbing Lapangan (DPL) ditunjuk untuk membimbing sebanyak 29-32 mahasiswa yang berkegiatan secara mandiri dalam kelompok kecil.

Karena pelaksanaannya secara daring dari ketiga program yang disyaratkan tersebut, maka sebagai implikasinya, kegiatan pembimbingan kepada mahasiswa KKNT juga dilakukan secara jarak jauh atau daring. Pelayanan secara daring kepada mahasiswa KKNT meliputi 1) konsultasi program yang akan dijalankan, 2) konsultasi kendala mahasiswa di lapangan dan bagaimana solusi pemecahannya, 3) diskusi mengenai luaran media pembelajaran untuk program wajib, 4) konsultasi luaran video sosialisasi 3M, 5) diskusi luaran kegiatan KKNT UPI (artikel berita, artikel ilmiah, video $3 \mathrm{M}$ ), dan beragam aktivitas lainnya. Luaran akhir KKNT yang disarankan UPI adalah berupa laporan akhir, artikel ilmiah untuk jurnal, atau book chapter (Buku Pedoman Kuliah Kerja Nyata Tematik Pencegahan Dan Penanggulangan Dampak Covid-19 Universitas Pendidikan Indonesia, n.d.). Mahasiswa dapat memilih salah satu dari ketiganya. Masing-masing DPL memiliki pola tersendiri dalam proses pembimbingan kepada mahasiswa agar luaran-luarannya dapat tercapai satu persatu (Djono, 2020), baik secara singkronus ataupun asingkronus. Dengan strategi pembimbingan yang tepat, maka mahasiswa selain mendapatkan momentum pengabdian lewat KKNT juga mampu meningkatkan kemampuan menulis buah hasil kegiatan pengabdian tersebut.

Penulis berkewajiban membimbing mahasiswa di Kelompok VIII yang beranggotakan mahasiswa/i UPI Kampus Purwakarta, Pendidikan Anak Usia Dini (PAUD) dan Prodi Pendidikan Guru \& Sekolah Dasar (PGSD). Tujuan dari kegiatan pelatihan ini adalah untuk memfasilitasi para mahasiswa dalam menyelesaikan salah satu luarannya, yaitu karya tulis ilmiah untuk jurnal dan Book chapter. Pelatihan ini berfokus bagaimana mengelola sitasi menggunakan reference manager tool. Dengan menggunakan tool, maka diharapkan kesalahan dalam menulis daftar Pustaka dapat diminimalisir dan penggunaan double style dalam suatu karya tulis dapat dihindari (C. Rahmawati et al., 2018). Berdasarkan observasi (Gambar 1), mahasiswa KKNT kelompok VIII mayoritas menggunakan fitur di Microsoft Word untuk membuat daftar 
Pustaka secara otomatis atau kutipan secara terorganisir (72,4\% atau 21 responden), sebanyak 6 orang $(20,7 \%)$ telah menggunakan reference manager Mendeley dan lainnya (memanfaatkan fitur Citation generator dari Google Scholar atau dari suatu website), disusul dengan End-Note hanya satu orang (3,4\%), dan sisanya adalah $0 \%$ dimana salah satunya adalah Zotero.

Zotero merupakan salah satu open-source tool yang dapat berkomunikasi dengan Microsoft Word atau Libreoffice dalam pengoperasiannya. Fitur yang ditawarkan beragam, diantaranya menawarkan berbagai style kutipan, dan mudah untuk digunakan (Aidid et al., 2020; Dwiningsih et al., 2019; Novitasari, 2019; H. Rahmawati \& Nuraini, 2019). Kegiatan pelatihan Zotero dilakukan oleh beberapa Civitas akademika seperti yang dilakukan oleh M.E.C. Anjali \& Z. Istiqomah (Anjali \& Istiqomah, 2019, 2020) dan A. Larasati (Larasati, 2020). Ketiga paper pengabdian masyarakat tersebut diselenggarakan secara tatap muka (offline). Disisi lain, telah banyak diselenggarakan pelatihan Zotero oleh beberapa Lembaga profit secara gratis ataupun berbayar secara daring via Zoom atau Google Meet. Kegiatan semacam ini telah banyak menarik partisipan yang mayoritas dari kalangan akademisi dimasa Pandemi Covid-19 seperti saat ini. Pelatihan Zotero yang diadakan oleh penulis juga secara daring, namun berbasis teks dengan menggunakan media Whatsapp Grup. Platform ini dipilih karena berbagai pertimbangan, diantaranya faktor koneksi internet di tempat tinggal masingmasing mahasiswa tidak merata. Bagi yang berada di daerah, maka tidak menjamin pelaksanaan pelatihan di Zoom akan lancar. Semua peserta pelatihan ini telah memiliki Whatsapp sehingga dapat mempermudah koordinasi.

Diharapkan setelah mengikuti pelatihan Zotero secara daring ini mahasiswa dapat terbantu dalam mengelola referensi untuk karya tulis ilmiah hasil KKNT mereka. Selain itu, dalam jangka panjang, mahasiswa KKNT kelompok VIII dapat mulai beralih ke tool reference manager dibandingkan dengan pemanfaatan fitur Microsoft Word dengan style kutipan yang terbatas. Zotero dengan fitur yang di-update secara berkala oleh Vendor mampu menyediakan ribuan styles (Idri, 2015; Kuglitsch, 2014; Nikam, 2015).

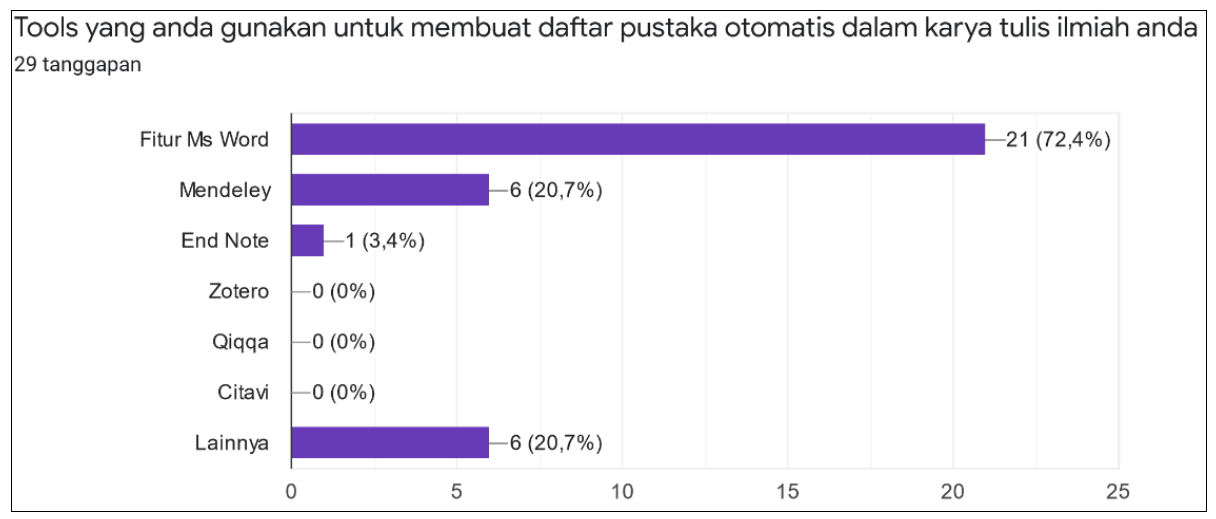

Gambar 1. Observasi awal mengenai tool citation manager yang digunakan oleh mahasiswa KKNT kelompok VIII sebelum kegiatan pelatihan

\section{METODE PELAKSANAAN}


Kegiatan pelatihan Zotero secara daring diawali dengan pemberian informasi kepada seluruh kelompok VIII bahwa akan ada pendampingan karya tulis ilmiah hasil KKNT seri pengelolaan referensi secara daring. Selanjutnya koordinasi dengan ketua kelompok VIII untuk membuat grup khusus pelatihan di Whatsapp agar tidak bercampur dengan grup utama. Whatsapp Group dibuat pada 12 Desember 2020. Sasaran kegiatan ini adalah seluruh anggota kelompok VIII, yaitu 34,5\% dari PGPAUD dan $65,5 \%$ dari PGSD UPI kampus Purwakarta (86,2\% perempuan dan 13,8\% laki-laki, ragu-ragu 0\%), seperti yang disajikan pada Gambar 2(a) dan Gambar 2(b).

Pelaksanaan kegiatan pada hari Rabu, 16 Desember 2020, pukul 20.00 WIB hingga 00.30 WIB atau dihitung 300 menit kegiatan KKNT. Kegiatan dilaksanakan pada malam hari karena pertimbangan waktu senggang mahasiswa, karena pagi mereka kuliah online dan KKNT daring kemudian sore melaporkan aktivitasnya di akun LPPM UPI serta mempersiapkan KKNT untuk keesokan harinya. Durasi pelatihan cukup lama dengan mempertimbangkan proses awal (instalasi) hingga hasil jadi, termasuk didalamnya ada troubleshooting saat kegiatan berlangsung. Durasi tersebut mencakup jeda antar materi sehingga peserta lain yang terkendala tidak akan tertinggal jauh akan materi pelatihan.

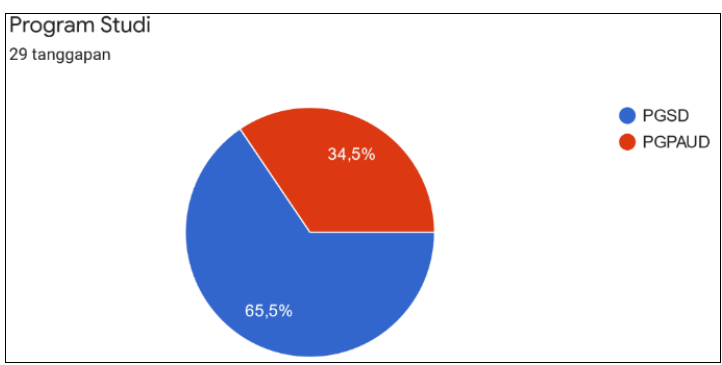

(a)

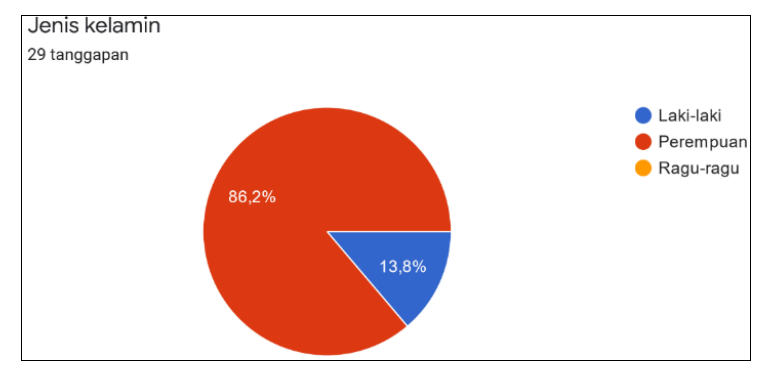

(b)

Gambar 2. Sebaran peserta pelatihan Zotero secara daring dalam kelompok VIII: (a) berdasarkan program studi; (b) berdasarkan jenis kelamin, yaitu laki-laki (13,8\%), perempuan $(86,2 \%)$ dan ragu-ragu $(0 \%)$.

Materi pelatihan yang disampaikan secara garis besar memuat tujuh kegiatan, yaitu: 1)Instalasi Zotero; 2) Troubleshooting apabila Zotero tidak dapat berkomunikasi dengan Microsoft Word; 3) Melengkapi Metadata; 4) Menyimpan file dalam bentuk Bibtex; 5) Membuat sitasi otomatis dengan menggunakan Zotero dengan sumber Paper jurnal, Conference dan Buku; 6) Membuat sitasi otomatis dengan menggunakan Zotero dengan sumber Online dan 7) Menambahkan style baru pada Zotero

\section{HASIL DAN PEMBAHASAN}

Kegiatan diawali dengan pembukaan melalui Whatsapp Group dan pengantar singkat tentang topik pelatihan (Gambar 3a), kemudian mahasiswa yang sedianya sudah standby di Whatsapp Group merespon dengan cepat (Gambar 3b). Metode penyampaian dari pelatihan ini adalah dengan mengirimkan file gambar yang merupakan konversi dari PDF materi (Gambar 3c). Outline materi kemudian disampaikan, yakni terdapat tujuh kompetensi yang diharapkan setelah pelatihan daring 
selesai (Gambar 3d). pelaksana melanjutkan materi yang secara urut disajikan sebagai berikut:

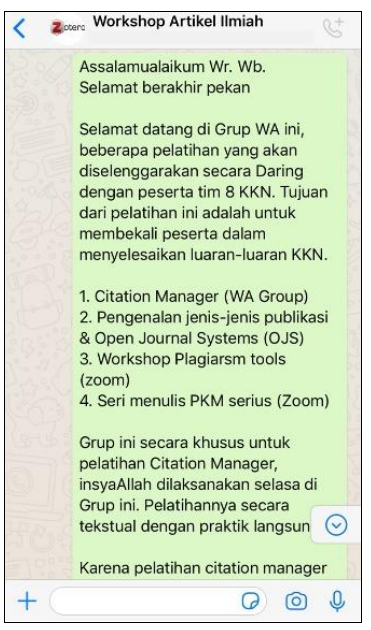

(a)

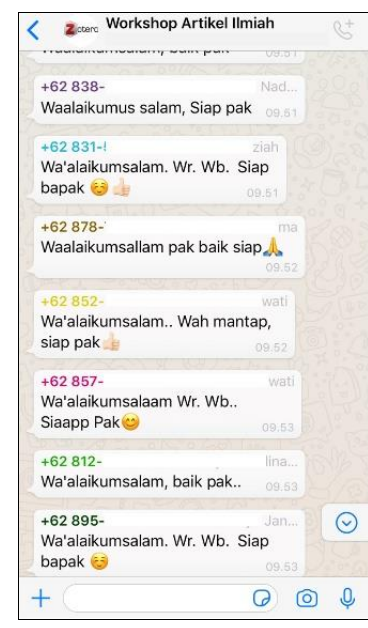

(b)

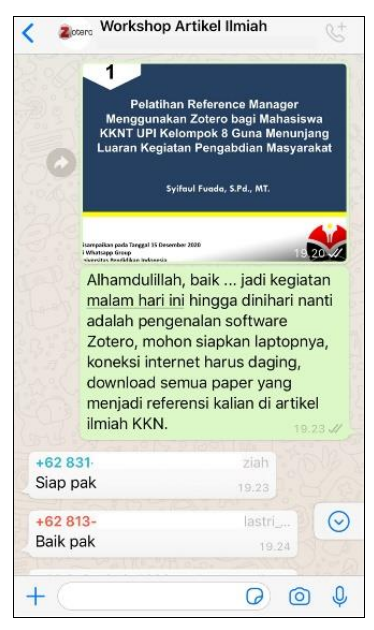

(c)

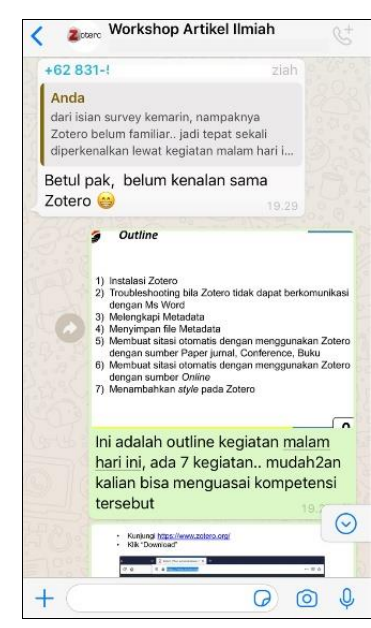

(d)

Gambar 3. Dokumentasi kegiatan pembukaan pelatihan Zotero di Whatsapp Group

\section{Instalasi Zotero}

Link dari laman Zotero (https://www.zotero.org/) dibagikan dan para peserta mengunduhnya di laptop/PC mereka masing-masing. Terdapat dua item pada laman download, yaitu Zotero 5.0 for Windows dan Zotero Connector. Pada materi pertama, opsi Zotero 5.0 for Windows dipilih. Pada tahap ini, terdapat kendala yaitu bagi mahasiswa yang tinggal di daerah "kampung", kesulitan dalam proses pengunduhan karena terkendala sinyal. Keluhan ini disampaikan oleh peserta pada percakapan Whatsapp Group (Gambar 4a). Mahasiswa yang didukung internet lancar, kemudian melakukan instalasi dan hasilnya dikirim di Whatsapp Group (Gambar 4b). Sambil menuggu proses instalasi mahasiswa lainnya, absensi kehadiran awal yang dibuat di Google Form dibagikan di Whatsapp Group. Pelaksana memberikan alokasi waktu download dan instalasi selama 1 jam untuk semua peserta pelatihan. Peserta diminta untuk memeriksa Zotero mereka masing-masing untuk memastikan bahwa versi yang diunduh merupakan yang terbaru. Karena apabila obsolete, Zotero tidak dapat berfungsi dengan baik, terutama saat membaca metadata dari paper yang dimasukkan. Zotero melakukan update/upgrading system secara berkala sehingga harus selalu di cek. Langkah berikutnya adalah, memeriksa integrasi ke Word Processor. Peserta harus memastikan bahwa ekstensi plugin adalah terbaru dan diposisikan ke Enable (Gambar 5). Apabila pada posisi Enable, keterangan tombol pada Zotero adalah Disable, begitu pula sebaliknya. 


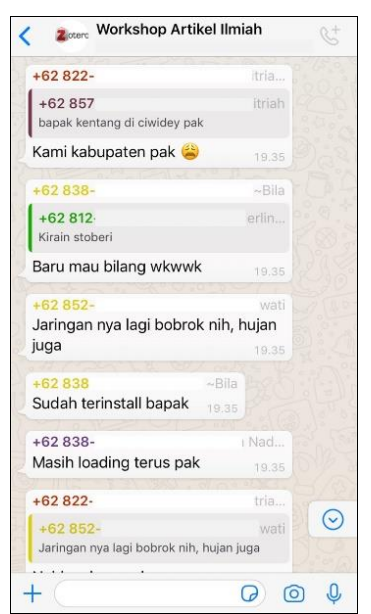

(a)

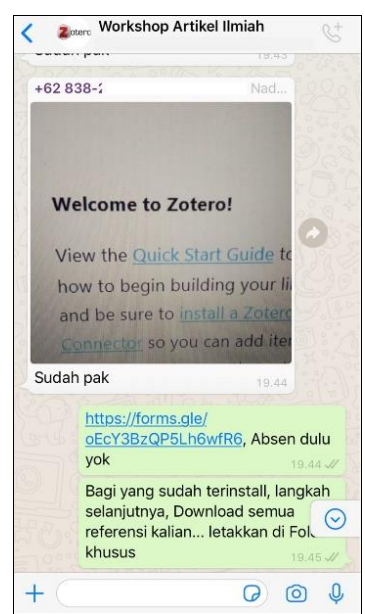

(b)

Gambar 4. Dokumentasi kegiatan pembukaan pelatihan Zotero di Whatsapp Group

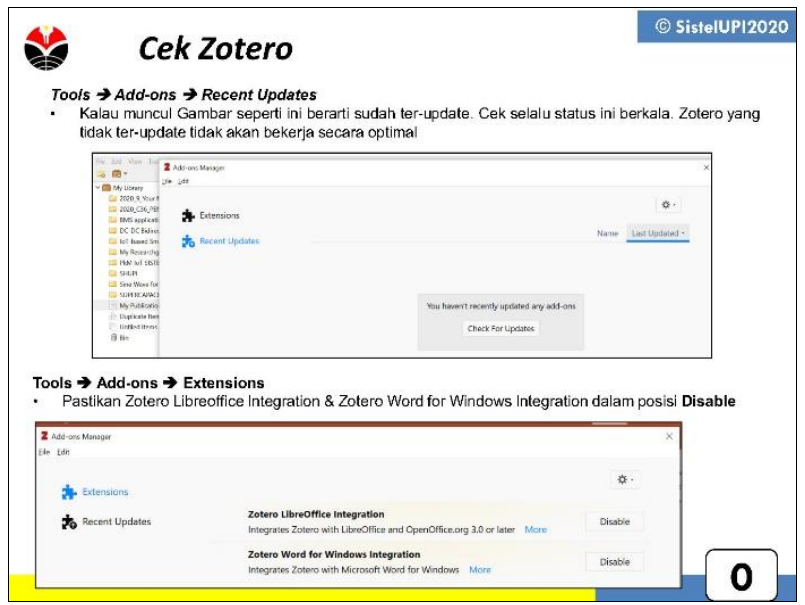

Gambar 5. Slide materi tentang informasi update status dari Zotero dan integrasi ke Word Processor (Libreoffice \& Microsoft Word dari Windows)

Trouble shooting apabila Zotero tidak dapat berkomunikasi dengan Microsoft Word

Setelah Sebagian besar peserta berhasil memasang Zotero di laptop mereka masing-masing, peserta diintruksikan untuk membuka Word Processor mereka (dalam hal ini adalah Microsoft Word), dimana file yang dibuka adalah artikel ilmiah masingmasing. Apabila instalasinya berhasil, maka menu Zotero akan muncul di Microsoft word (Gambar 5a). Pada tahap ini, terdapat beberapa mahasiswa yang mengalami masalah dengan Zotero, yaitu tidak dapat terhubung dengan Microsoft Word (Gambar 6b). Hal ini merupakan masalah umum yang terjadi pada Zotero (Kratochvíl, 2017; Word Processor Plugin Manual Installation [Zotero Documentation], n.d.). Proses trouble shooting perlu dilakukan. Namun, pada pelatihan ini, pelaksana tidak memberikan instruksi secara tekstual bagaimana cara mengatasinya. Pelaksana melakukan absensi berapa mahasiswa yang secara persis belum berhasil pada tahap ini. Selanjutnya, pelaksana meminta kepada peserta agar memilih opsi Enable di Zotero sambil membagikan link Youtube berbahasa Indonesia di Whatsapp Group. Peserta diharuskan untuk mengikuti Langkah-langkah praktisnya (Gambar 6c). Sejauh ini Zotero (versi 5.0) belum mendukung integrasi dengan WPS (Gambar 6d), sehingga mahasiswa Nonuser Microsoft dapat memasang Libreoffice. 


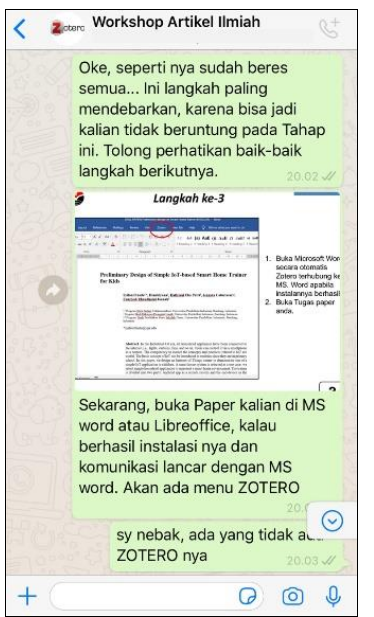

(a)

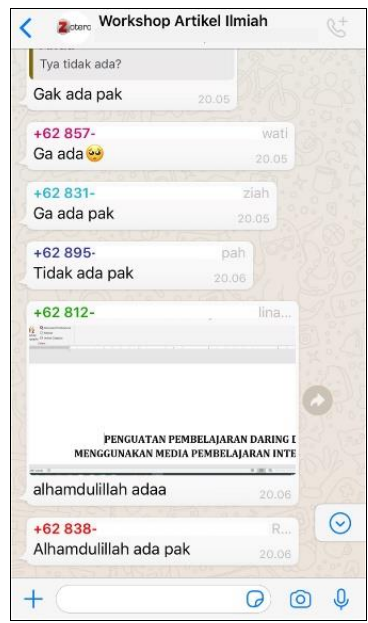

(b)

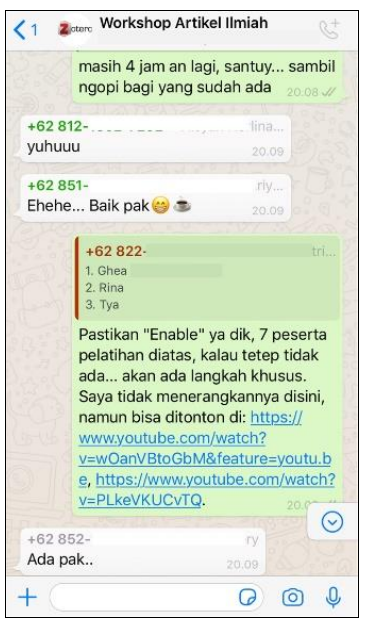

(c)

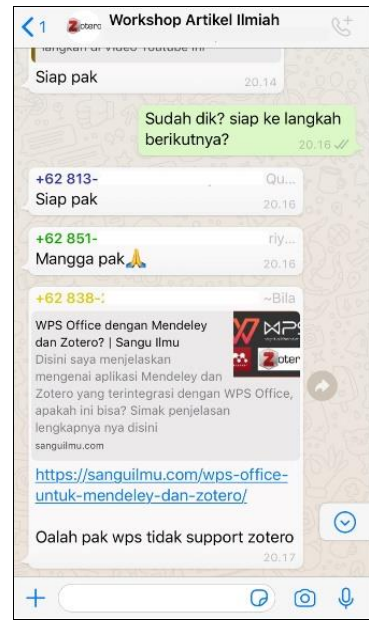

(d)

Gambar 6. Dokumentasi pematerian tentang Troubleshooting

\section{Melengkapi Metadata}

Tahap selanjutnya, peserta membuat folder di Zotero masing-masing. Lalu, peserta membuka folder khusus yang berisi tentang paper-paper yang menjadi referensi untuk artikel ilmiahnya.

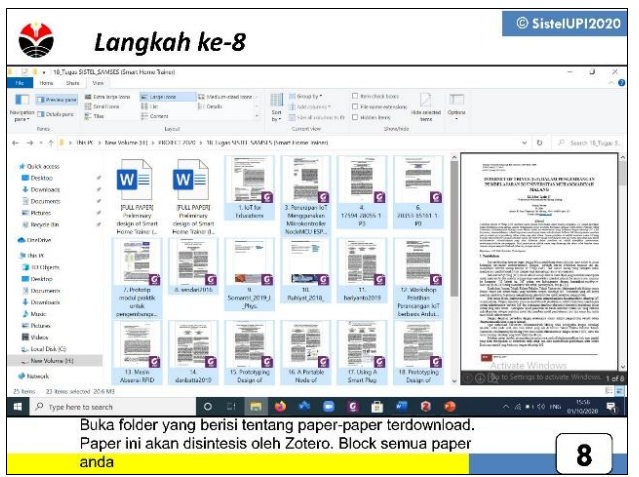

(a)

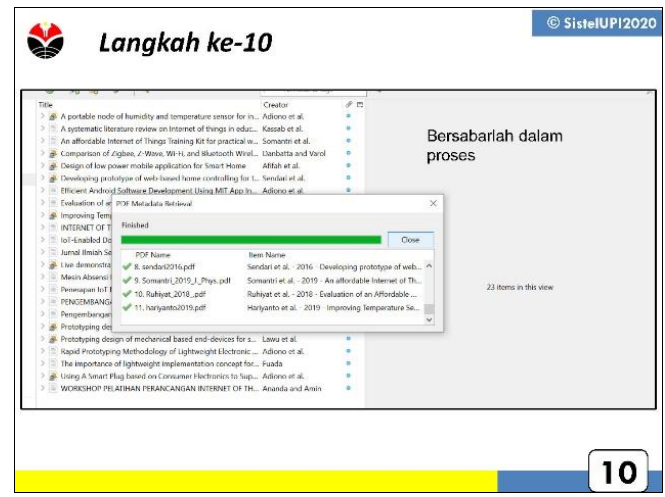

(c)

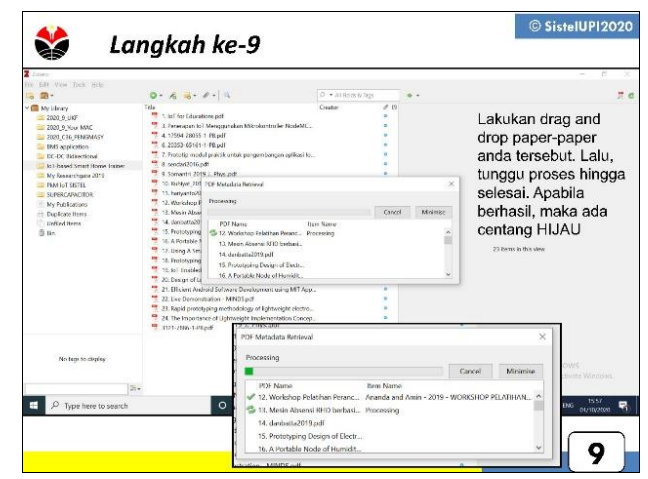

(b)

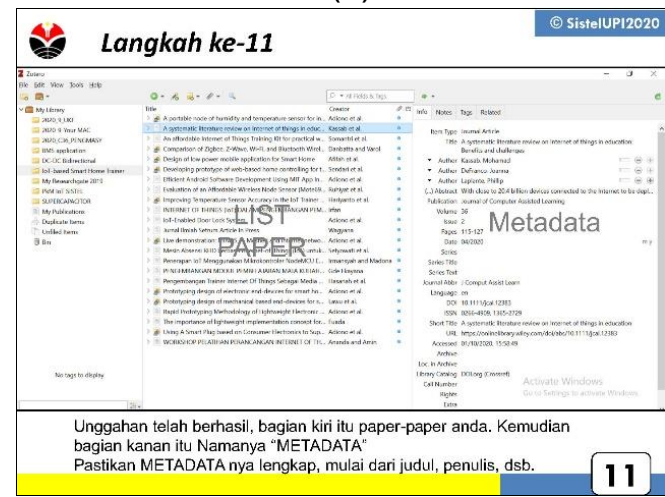

(d)

Gambar 7. Slide materi ke-3: (a) proses drag dan (b) drop paper-paper ke Zotero, (c) proses sintesis, (d) pengenalan bagian-bagian lembar kerja Zotero

Peserta melakukan drag \& drop semua paper seperti langkah pada Gambar 7a, ke Zotero (Gambar 7b). Zotero akan membaca Metadata dari masing-masing paper 
yang durasinya sesuai dengan jumlah paper, apabila paper yang disintesis banyak, maka prosesnya akan lama begitu pula sebaliknya (Gambar 7c). Apabila berhasil, maka bagian kanan Zotero akan menampilkan Metadata (Gambar 7d). Peserta diwajibkan untuk melengkapi metadata (Gambar 8a) bagi paper referensi yang tidak lengkap (Gambar 8b).

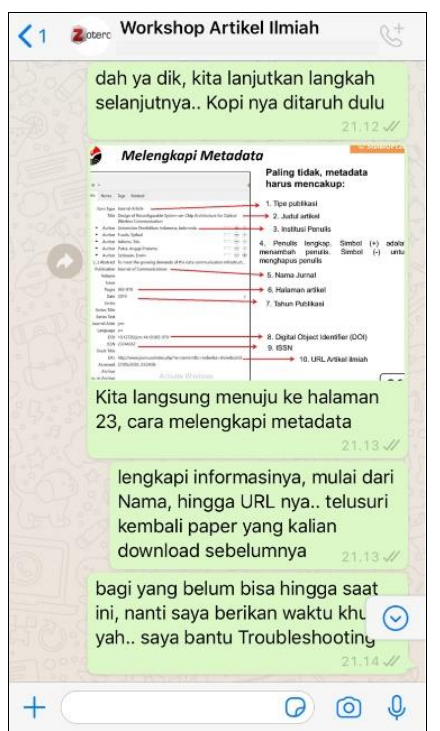

(a)

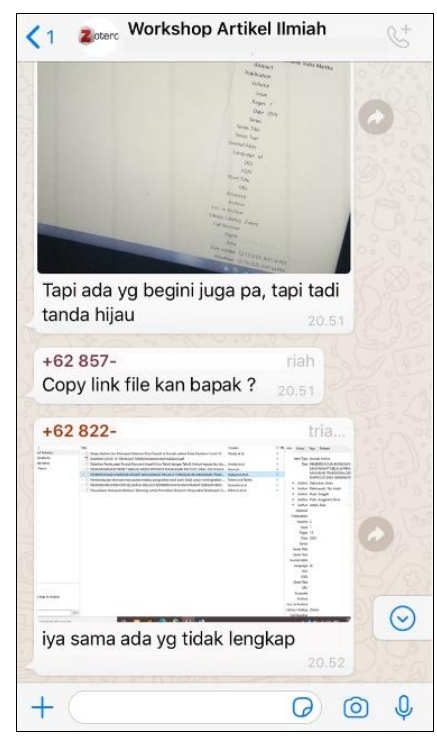

(b)

Gambar 8. (a) Dokumentasi pematerian tentang Metadata di Zotero dan (b) interaksi dengan peserta pelatihan

\section{Menyimpan file Metadata}

Materi ke-4 adalah tentang prosedur menyimpan metadata yang telah disintesis oleh Zotero seperti yang ditunjukkan pada Gambar 9, sehingga dapat meminimalisir hilangnya metadata-metadata apabila terjadi hal yang tidak diinginkan. Peserta dapat menyimpan (import) file dalam format Bibtex, RIS, Zotero, RDF, dan lain sebagainya. File tersebut dapat diekspor di Zotero yang baru saja terinstal di laptop/PC lain sehingga list metadata dapat dibaca. Dengan demikian, peserta tidak perlu mensintesis paper-paper dari awal lagi.

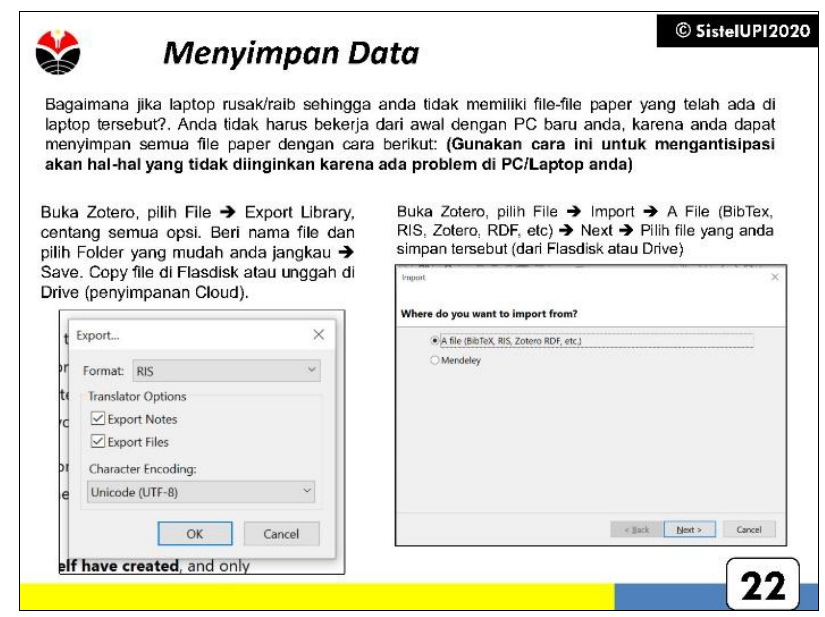

Gambar 9. Slide materi tentang prosedur impor dan ekspor file Bibtex pada Zotero 


\section{Membuat daftar pustaka otomatis dengan menggunakan Zotero dengan sumber Paper jurnal, Conference, Buku}

Proses melakukan sitasi dan daftar Pustaka pada Zotero sangat mudah. Pada materi ini, literatur yang dirujuk adalah bersumber dari jurnal, konferensi, atau buku yang memiliki metadata. Terdapat enam Langkah seperti yang ditunjukkan pada Gambar 10(a) hingga 10(d). Peserta yang tidak ada masalah dengan Zotero mereka, dapat mengikuti proses ini dengan cepat.

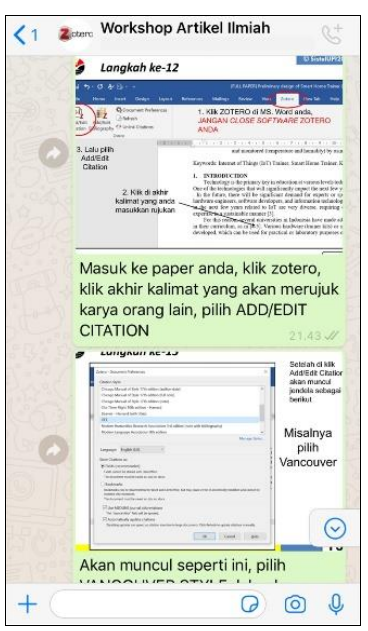

(a)

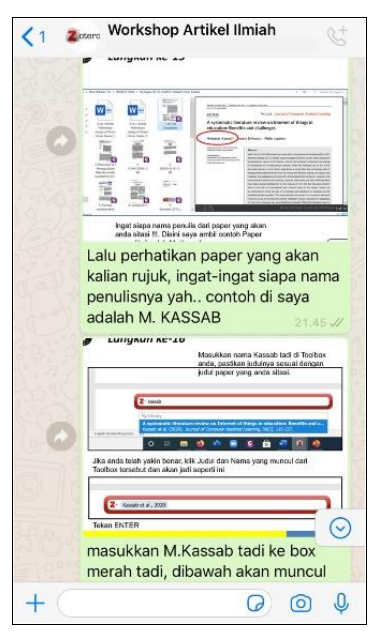

(b)

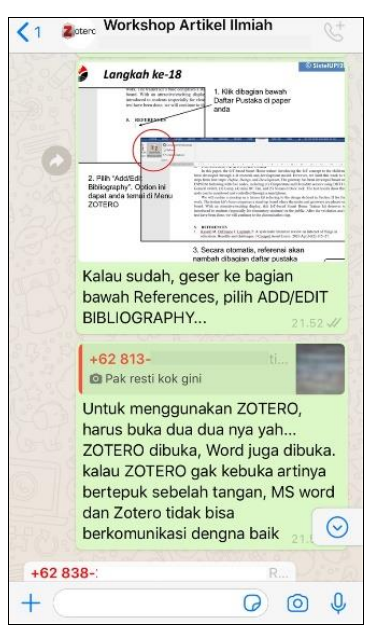

(c)

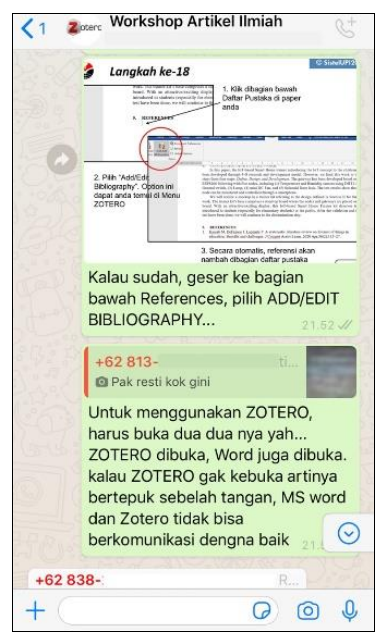

(d)

Gambar 10. Dokumentasi pematerian tentang proses membuat sitasi dan daftar Pustaka otomatis dengan sumber berupa file PDF di Zotero

\section{Membuat sitasi otomatis dengan menggunakan Zotero dengan sumber Online}

Materi selanjutnya adalah membuat sitasi dan daftar Pustaka dengan literatur berupa website. Langkah pertama, pelaksana membagikan Link laman Zotero (https://www.zotero.org/) dan kali ini memilih opsi Zotero Connector (Gambar 11a). Pemasangan Connector dilakukan di Mozila Firefox. Pada Zotero, proses mensitir sumber online sama dengan cara mensitir sumber dari jurnal, yang membedakan adalah saat memasukkan referensi. pada tahap ini dipilih nama link website (Gambar 11b) bukan nama penulisnya. Apabila proses integrasi Connector dan Web browser berhasil, terdapat icon seperti kertas dibagian pojok kanan atas Web browser (Gambar 11c). Terdapat beberapa peserta yang belum memahami proses ini, sehingga tutorial dilanjutkan dengan memberikan foto untuk menjelaskannya secara step-by-step (Gambar 11d) 


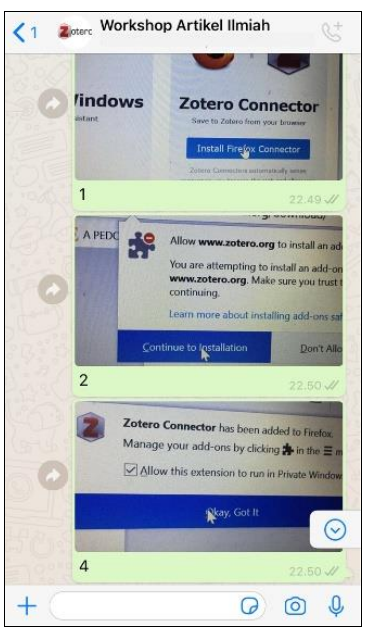

(a)

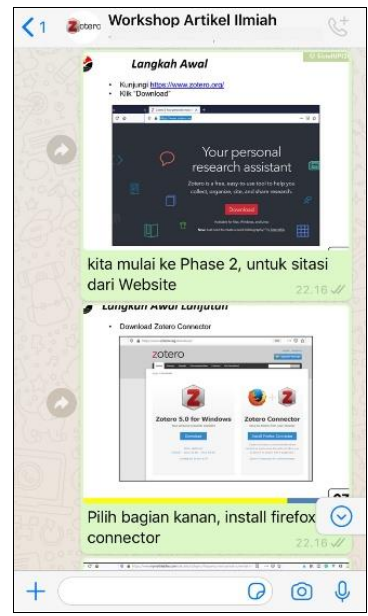

(b)

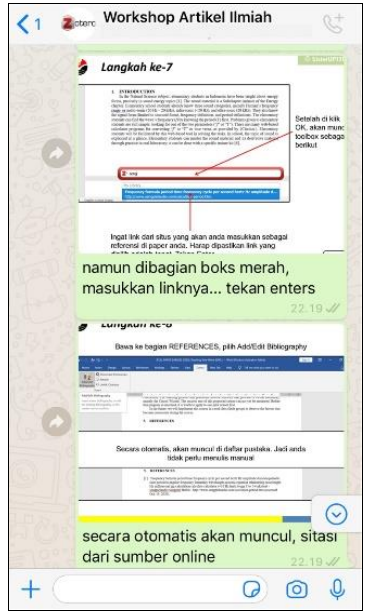

(c)

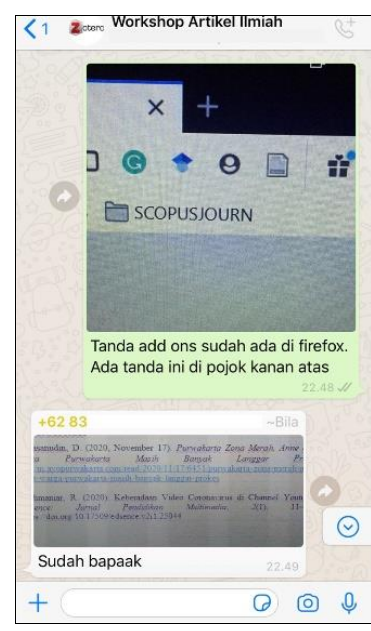

(d)

Gambar 11. Dokumentasi pematerian tentang proses membuat sitasi dan daftar Pustaka otomatis dengan sumber berupa link website di Zotero

\section{Menambahkan style pada Zotero}

Materi terakhir adalah bagaimana cara menambahkan styles yang tidak tersedia di default style. Pelaksana mengemas dalam bentuk challenge kepada para peserta sehingga mereka berusaha untuk mencari sendiri bagaimana menambah citation style dari IOP Publishing, yaitu Journal of Physics: Conference Series (Gambar 12a). Pada proses ini, hanya satu peserta yang berhasil (Gambar 12b). Reward diberikan kepadanya (Gambar 12b dan Gambar 12d).

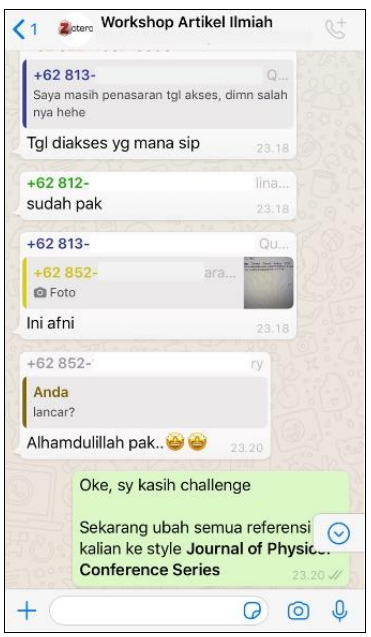

(a)

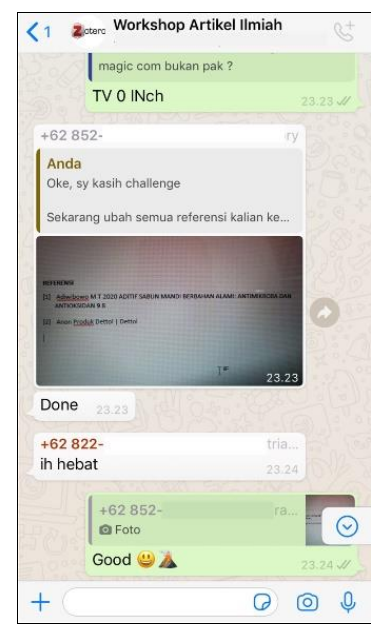

(b)

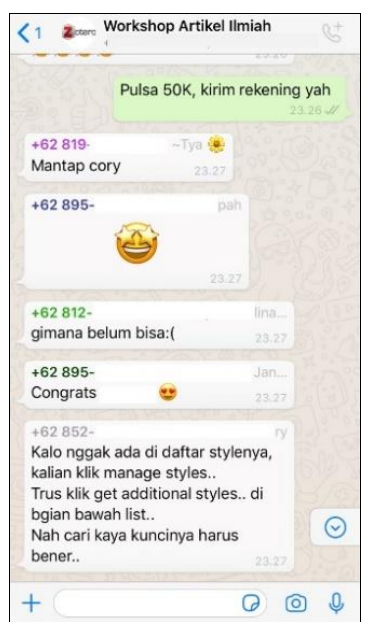

(c)

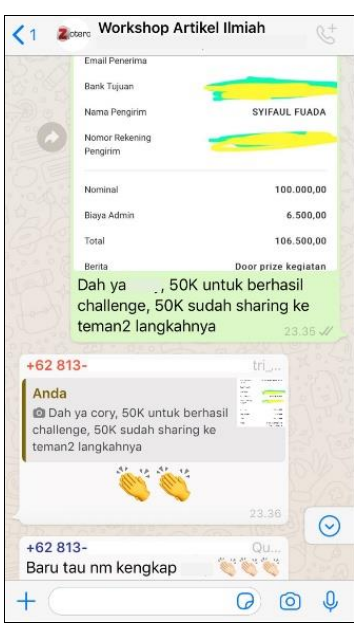

(d)

Gambar 12. Dokumentasi pemberian tantangan kepada para peserta dan reward

Google Form untuk absensi akhir kegiatan diberikan saat penutupan, hasil absensi digunakan oleh pelaksana sebagai alat bantu untuk menghitung jam kegiatan KKNT dari mahasiswa. Dalam form, juga disediakan unggah laporan hasil pelatihan yang berupa screenshoot daftar Pustaka dengan style IEEE dan Journal of Physics: Conference Series. Pelaksana dapat mengukur tingkat keberhasilan peserta pelatihan melalui dokumen laporan tersebut. Gambar 13 merupakan sampel hasil kegiatan dari salah satu mahasiswa KKNT Kelompok VIII yang mengikuti pelatihan. Setelah mencapai 
300 menit, pelaksana segera menutup pelatihan (Gambar 14). Keesokan harinya, pelaksana melakukan evaluasi pascapelatihan.

Tabel 1 merupakan hasil pengamatan pelaksana terkait aktivitas mahasiswa saat pelatihan Zotero berlangsung di Whatsapp Group. Dari 32 total mahasiswa kelompok VIII, hanya 29 mahasiswa yang bersedia mengikuti karena tiga diantaranya jarang aktif mengikuti diskusi di Whatsapp Group utama. Saat kegiatan berlangsung, 4 mahasiswa berhalangan hadir karena sebab tertentu. Dari 25 mahasiswa, 19 mahasiswa mengikuti hingga akhir kegiatan (pukul 00.00 WIB) dan hanya 13 mahasiswa yang berhasil hingga tahap akhir. Adapun 6 mahasiswa tidak berhasil karena masalah utamanya ada di software Zotero mereka, yaitu tidak dapat terkoneksi dengan word processor mereka (Microsoft Word, WPS, Libreoffice). Mereka telah mencoba berbagai Langkah yang disarankan namun hingga pelatihan selesai, masih belum menemukan titik terang. Solusi yang ditawarkan, mereka dapat menggunakan citation manager selain Zotero, diantaranya EndNote, Mendeley, Qiqqa, Citavi, Refworks, dsb. Pada dasarnya, semua tools tersebut memiliki fungsi dasar yang sama, perbedaannya terletak pada fitur dan pengoperasiannya saja (Kaur \& Dhindsa, 2016; Murimboh \& Hollingdale, 2012). Tabel 2 merupakan capaian ke-13 mahasiswa peserta pelatihan.

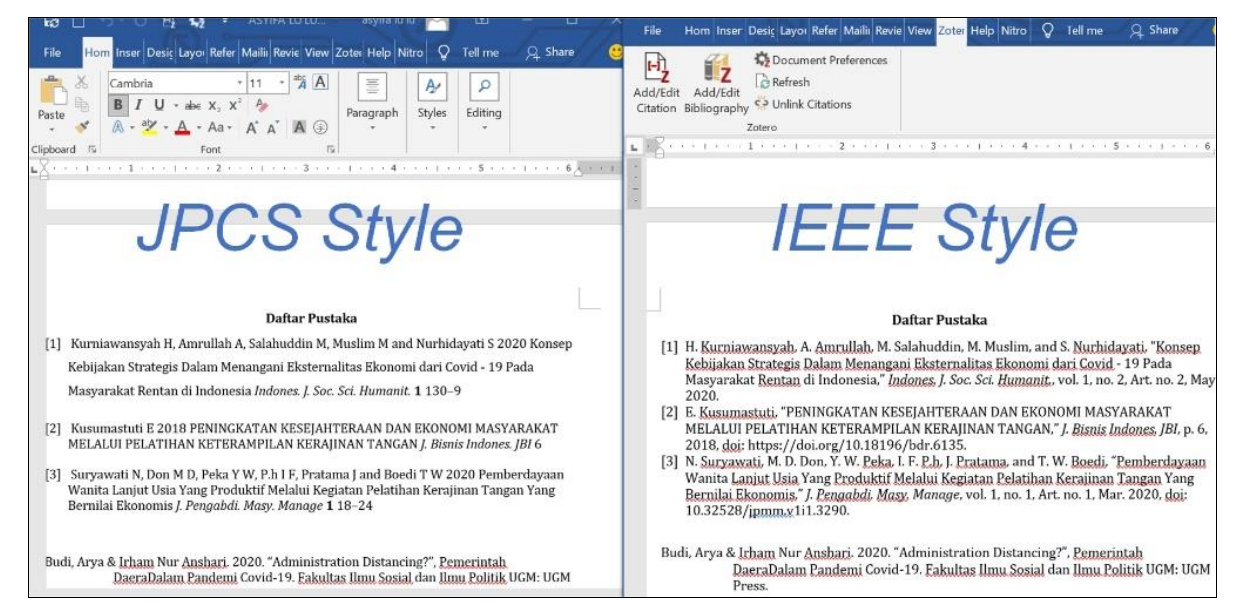

Gambar 13. Hasil kegiatan pelatihan Zotero dari salah satu mahasiswa 


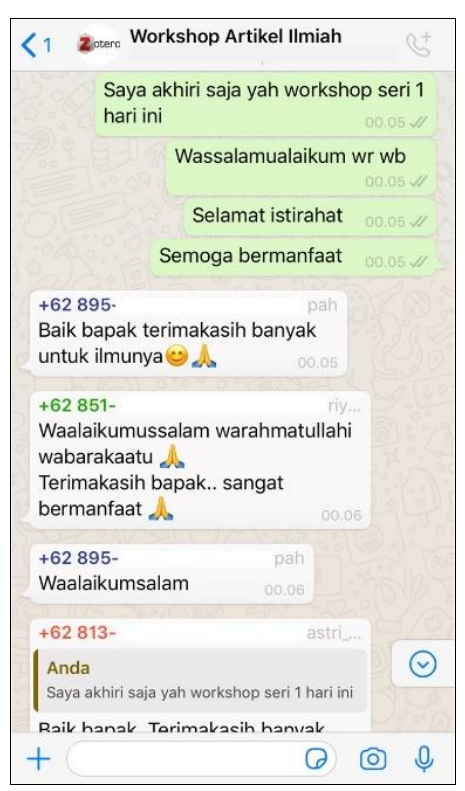

(a)

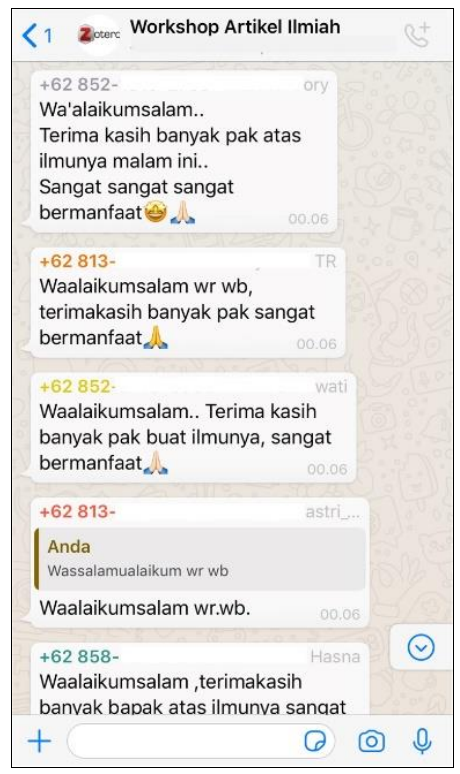

(b)

Gambar 14. Dokumentasi kegiatan penutupan pelatihan Zotero di Whatsapp Group

Tabel 1. Hasil pengamatan selama pelatihan Zotero

\begin{tabular}{|c|c|c|}
\hline No & Peserta & Jumlah \\
\hline 1 & $\begin{array}{l}\text { Mahasiswa KKNT UPI yang tergabung di } \\
\text { Kelompok VIII }\end{array}$ & 32 Mahasiswa \\
\hline 2 & $\begin{array}{l}\text { Peserta yang mendaftar kegiatan pelatihan } \\
\text { Zotero dan tergabung di Whatsapp Group } \\
\text { khusus }\end{array}$ & 29 Mahasiswa \\
\hline 3 & $\begin{array}{l}\text { Peserta yang mengisi daftar kehadiran saat } \\
\text { kegiatan berlangsung }\end{array}$ & $\begin{array}{l}25 \text { Mahasiswa } \\
\text { (4 Mahasiswa berhalangan hadir) }\end{array}$ \\
\hline 4 & $\begin{array}{l}\text { Mahasiswa yang mengikuti kegiatan hingga akhir } \\
\text { (lapor hasil pelatihan di Google Form) }\end{array}$ & $\begin{array}{l}19 \text { Mahasiswa } \\
\text { ( } 6 \text { Mahasiswa tidak aktif dalam } \\
\text { kegiatan, menghilang, dan tidak } \\
\text { report hasil workshop hingga } \\
\text { batas waktu yang ditentukan) }\end{array}$ \\
\hline 5 & $\begin{array}{l}\text { Mahasiswa yang berhasil dalam kegiatan } \\
\text { pelatihan }\end{array}$ & 13 Mahasiswa \\
\hline 6 & $\begin{array}{l}\text { Mahasiswa yang tidak berhasil dalam kegiatan } \\
\text { pelatihan }\end{array}$ & 6 Mahasiswa \\
\hline
\end{tabular}

Tabel 2. Perbandingan pra dan pascapelatihan Zotero

\begin{tabular}{|c|l|l|}
\hline No & \multicolumn{1}{|c|}{ Sebelum Pelatihan } & \multicolumn{1}{c|}{ Setelah Pelatihan } \\
\hline 1 & $\begin{array}{l}\text { Mahasiswa KKNT UPI yang } \\
\text { tergabung di Kelompok VIII belum } \\
\text { pernah menggunakan Zotero }\end{array}$ & Mahasiswa mampu mengoperasikan Zotero \\
\hline \multirow{2}{*}{2} & $\begin{array}{l}\text { Mahasiswa KKNT UPI yang } \\
\text { tergabung di Kelompok VIII belum } \\
\text { memahami tentang Metadata dari } \\
\text { suatu paper yang telah terpublikasi. } \\
\text { Selain itu, sitasi yang mereka } \\
\text { gunakan sebelum pelatihan banyak } \\
\text { yang miss (tidak lengkap) }\end{array}$ & $\begin{array}{l}\text { Mahasiswa memahami tentang Metadata dan } \\
\text { bagaimana melengkapi di Zotero sehingga sitasi } \\
\text { yang digunakan adalah format yang utuh, } \\
\text { mencakup informasi dari nama lengkap authors, } \\
\text { judul paper, nama publikasi, volume, nomor, } \\
\text { halaman, ISSN, bulan dan tahun terbit, serta } \\
\text { Digital Object Identifier (DOI). }\end{array}$ \\
\hline
\end{tabular}




\begin{tabular}{|c|l|l|}
\hline 3 & $\begin{array}{l}\text { Mahasiswa KKNT UPI yang } \\
\text { tergabung di Kelompok VIII pada } \\
\text { awalnya merasa kesulitan bila } \\
\text { menggunakan referensi dari suatu } \\
\text { website }\end{array}$ & $\begin{array}{l}\text { Mahasiswa mampu membuat sitasi yang } \\
\text { bersumber dari sumber online dengan mudah. } \\
\text { Mereka hanya tinggal mengambil referensi } \\
\text { dengan melakukan klik kanan dan save to } \\
\text { Zotero pada website yang dibuka saat itu. }\end{array}$ \\
\hline 4 & $\begin{array}{l}\text { Mahasiswa mulai menggunakan Zotero karena } \\
\text { menurutnya lebih praktis. Mereka tidak perlu } \\
\text { input informasi di Microsoft Word. Dengan } \\
\text { Zotero, mereka hanya tinggal Drag \& Drop } \\
\text { menggunakan Windows, mereka } \\
\text { memanfaatkan fitur Microsoft Word } \\
\text { dalam membuat daftar Pustaka } \\
\text { otomatis }\end{array}$ & $\begin{array}{l}\text { semua paper yang menjadi rujukan maka } \\
\text { informasi mengenai paper tersebut secara } \\
\text { otomatis dibaca oleh Zotero. Apabila tidak } \\
\text { lengap Metadatanya, mereka tinggal } \\
\text { melengkapi saja. Disisi lain, Zotero } \\
\text { menyediakan reference styles yang jauh lebih } \\
\text { lengkap }\end{array}$ \\
\hline 5 & $\begin{array}{l}\text { Terdapat mahasiswa yang telah } \\
\text { memanfaatkan reference manager } \\
\text { selain Zotero }\end{array}$ & $\begin{array}{l}\text { Mahasiswa beralih ke Zotero karena } \\
\text { menurutnya lebih mudah digunakan } \\
\text { dibandingkan reference manager yang telah } \\
\text { digunakan sebelumnya }\end{array}$ \\
\hline
\end{tabular}

\section{Faktor pendukung dan penghambat program}

Peserta yang mengikuti pelatihan ini adalah mahasiswa semester 7 , sehingga dasar-dasar merujuk karya tulis ilmiah serta berbagai style kutipan sudah dipahami oleh mereka dengan baik, terutama didapatkan pada mata kuliah metodologi penelitian. Selain itu, mahasiswa sudah terbiasa untuk tidak menulis daftar Pustaka dan kutipan secara manual. Mereka menggunakan fitur dari Microsoft word, Citation generator dari Google Scholar ataupun dari suatu web penyedia layanan sitasi. Dengan demikian, mahasiswa mudah dalam mengikuti pelatihan ini meskipun instruksinya secara tekstual di Whatsapp karena dasar-dasarnya sudah mereka pahami sebelumnya. Whatsapp merupakan salah satu media komunikasi alternatif pelatihan daring (Kusnaeni, 2020; Pahriah \& Safitri, 2020). Sedangkan faktor penghambat pelatihan adalah sebagai berikut:

- Kegiatan pelatihan terlambat 30 menit dari jadwal yang ditentukan karena terjadi trouble pada pemateri. Namun, hal tersebut bukan menjadi masalah bagi peserta karena mereka setelah sholat Isya sambil menyiapkan Laptop/PC serta merapikan folder yang berisi paper-paper untuk disitasi menggunakan Zotero.

- Akses internet dari peserta menjadi salah satu kendala dari pelatihan ini. Apabila pelatihan serupa diadakan kembali, hal tersebut dapat disiasi dengan membagi pelatihan menjadi dua sesi. Sesi pertama adalah pengunduhan dan instalasi Zotero dilaksanakan pada pagi hari sedangkan sesi kedua adalah materi inti yang dilaksanakan pada malam harinya.

- Di awal pelatihan, peserta kebingunan terkait posisi Enable ke Disable. Hal ini menjadi saran kepada Vendor agar menyediakan indikator berupa perubahan warna tombol, sehingga pengguna dapat membedakan mana posisi Enable dan mana posisi Disable. 
- Zotero Mahasiswa ada yang tidak dapat tersambung dengan Microsoft Word meskipun telah diselesaikan melalui berbagai Langkah seperti yang disarankan di Youtube. Sehingga mereka hanya mengikuti chat di Whatsapp Group tanpa mempraktikkannya.

- Terdapat dua mahasiswa yang tidak menggunakan Microsoft Word, mereka menggunakan WPS yang tidak support Zotero. Agar mereka dapat mengikuti pelatihan, mereka harus mengunduh Libreoffice. Hanya satu mahasiswa berhasil memfungsikan Zotero di Libreoffice, satu lainnya belum dapat berkomunikasi dengan Zotero sehingga ia tetap menggunakan Mendeley.

- Terdapat mahasiswa dengan spesifikasi Laptop yang kurang baik sehingga tertinggal jauh. Namun, karena pelaksanaannya secara tekstual, mereka dapat melakukan scroll up percakapan di Whatsapp Group sehingga dapat menyusul kembali.

- Mahasiswa kesulitan mencari ISSN dan DOI untuk melengkapi Metadata, karena tidak semua artikel ilmiah dicantumkan dipapernya sehingga harus mencari ke Jurnal yang bersangkutan.

\section{KESIMPULAN DAN SARAN}

Berdasarkan pelatihan Zotero secara daring via Whatsapp dapat disimpulan bahwa meskipun bentuk pelatihannya secara instruksional berbasis teks, hampir sepertiga mahasiswa berhasil hingga tahap akhir. Beberapa mahasiswa tidak dapat mengikuti karea merasa tertinggal jauh dan masalah pada Zotero tidak dapat terintegrasi dengan Microsoft Word. Salah satu sisi positif yang diraih dengan penyelenggaraan di Whatsapp Group adalah para peserta dapat mendokumentasi kegiatan dengan hemat bandwidth karena berbasis teks dibandingkan merekam video via Zoom apabila penyampaian materi secara verbal. Pengendalian chat oleh pemateri diperlukan agar chat tidak crowded, pesan-pesan yang tidak perlu dapat diminimalisir sehingga peserta lain yang kesulitan dalam satu step tertentu tidak panik dan masih memiliki semangat untuk melanjutkan prosesnya. Apabila tetap tidak dapat disaring, maka peserta masing-masing dapat menghapus chat yang tidak perlu secara langsung dan hanya menyisakan materi-materi instruksi di Whatsapp Group.

\section{UCAPAN TERIMA KASIH}

Penulis mengucapkan terimakasih kepada LPPM Univeristas Pendidikan Indonesia dan juga kepada teman-teman Dosen Pembimbing Lapangan UPI Purwakarta yang telah mendukung kegiatan pelatihan ini.

\section{DAFTAR PUSTAKA}

Aidid, M. K., Bustan, M. N., \& Ruliana. (2020). Manajemen Referensi dengan Aplikasi Zotero. Jurnal Dedikasi, 22(2), 126-128.

Anjali, M. E. C., \& Istiqomah, Z. (2019). Implementasi Pelatihan Aplikasi Zotero di Perpustakaan Universitas Muhammadiyah Yogyakarta Bagi Mahasiswa Magister Ilmu Pemerintahan. Publication Library and Information Science, 3(2), 97-103. 
Anjali, M. E. C., \& Istiqomah, Z. (2020). Meningkatkan literasi informasi penulisan karya ilmiah mahasiswa melalui pelatihan zotero. Berkala IImu Perpustakaan dan Informasi, 16(2), 198-210. https://doi.org/10.22146/bip.v16i2.104

Buku Pedoman Kuliah Kerja Nyata Tematik Pencegahan dan Penanggulangan Dampak Covid-19 Universitas Pendidikan Indonesia. (n.d.). Retrieved 8 January 2021, from http://lppm.upi.edu/berita/detail/buku-pedoman-kuliah-kerja-nyata-tematikpencegahan-dan-penanggulangan-dampak-covid19

Djono, D. (2020). Implementasi Adaptasi Baru melalui KKN UNS di Era Covid 19. DEDIKASI: Community Service Reports, 2(2), 533-536. https://doi.org/10.20961/dedikasi.v2i2.45927

Dwiningsih, K., Tukiran, T., \& Made Sanjaya, I. gusti. (2019). Peningkatan Kualitas Publikasi IImiah dan Penelitian Bagi Guru SMA Melalui Pelatihan Pemanfaatan Software Zotero. Jurnal ABDI, 4(2), 85. https://doi.org/10.26740/ja.v4n2.p85-90

Idri, N. (2015). Zotero Software: A Means of Bibliographic Research and Data Organisation; Teaching Bibliographic Research. Arab World English Journal (AWEJ), 1(2), 124-133. https://doi.org/10.2139/ssrn.2843984

info, S. (n.d.). Perbedaan KKN Tematik Dengan KKN Posdaya. Sepenggal Info. Retrieved 8 January 2021, from https://sepenggal.info/perbedaan-kkn-tematikdan-kkn-posdayal

Kaur, S., \& Dhindsa, K. S. (2016). Comparative study of citation and reference management tools: Mendeley, Zotero and ReadCube. 2016 International Conference on ICT in Business Industry \& Government (ICTBIG), 1-5. https://doi.org/10.1109/ICTBIG.2016.7892715

Kratochvíl, J. (2017). Comparison of the Accuracy of Bibliographical References Generated for Medical Citation Styles by EndNote, Mendeley, RefWorks and Zotero. The Journal of Academic Librarianship, 43(1), 57-66. https://doi.org/10.1016/j.acalib.2016.09.001

Kuglitsch, R. (2014). More than a Citation Manager: Zotero for Scalable Embedded Librarianship and Instructional Assessment. Library Instruction West 2014, 118.

Kusnaeni, A. (2020). Pelatihan Bisnis Fashion Melalui Whatsapp Dalam Meningkatkan Pemberdayaan Bagi UMKM Cimahi. Comm-Edu (Community Education Journal), 3(1), 42-49. https://doi.org/10.22460/comm-edu.v3i1.3694

Larasati, A. (2020). Peningkatan Kemampuan Mengoperasikan Reference Management Software Zotero dan End-Note Untuk Guru SMKN 6 Malang. Jurnal Pengabdian Kepada Masyarakat, 26(1), 28-33. https://doi.org/10.24114/jpkm.v26i1.15777

Murimboh, J. D., \& Hollingdale, C. R. (2012). Zotero: A Reference Manager for Everyone. Journal of Chemical Education, 89(1), 173-174. https://doi.org/10.1021/ed1010618

Nikam, K. (2015). Zotero Software for Effective Reference Management. Journal of Advancements in Library Sciences, 2(1), 36-47.

Novitasari, N. F. (2019). Pelatihan Penulisan Artikel Ilmiah: Menuju Guru Berkualitas. Jurnal Pengabdian Pada Masyarakat, 4(3), 255-266. https://doi.org/10.30653/002.201943.152 
Pahriah, \& Safitri, B. R. A. (2020). Pelatihan dan Pendampingan Penulisan Buku Ajar Bagi Dosen Pemula Melalui Whatsapp Group. Lumbung Inovasi: Jurnal Pengabdian Kepada Masyarakat, 5(1), 15-23.

Rahmawati, C., Meliyana, M., Yuliana, Y., \& Zain, H. (2018). Pelatihan Software Mendeley Dalam Peningkatan Kualitas Artikel Ilmiah Bagi Dosen. Jurnal Pengabdian Kepada Masyarakat, 8(1), 30-36. https://doi.org/10.30999/jpkm.v8i1.200

Rahmawati, H., \& Nuraini, M. W. (2019). Analisis Perbandingan Aplikasi Manajemen Referensi Zotero 5.0.66. Dan Endnote X9. Publication Library and Information Science, 3(2), 80-86. https://doi.org/10.24269/pls.v3i2.2112

Word processor plugin manual installation [Zotero Documentation]. (n.d.). Retrieved 9 January 2021, from https://www.zotero.org/support/word_processor_plugin_manual_installation 